\title{
Vagus Nerve Stimulation for Epilepsy: The Notre-Dame Hospital Experience
}

\author{
Mehdi Qiabi, Alain Bouthillier, Lionel Carmant, Dang Khoa Nguyen
}

\begin{abstract}
Purpose: Retrospective study assessing the efficacy and tolerability of vagus nerve stimulation (VNS) for the treatment of refractory epilepsy at Notre-Dame Hospital. Methodology: Chart review of all adult epileptic patients treated by VNS with $\geq 1$ year follow-up. Responders were defined as patients with $\geq 50 \%$ reduction of baseline seizure frequency. Results: Thirty-four patients (14M ; mean age $=29.9 \mathrm{yrs})$ received a VNS. Sub-pectoralis implantation $(\mathrm{n}=25)$ was more frequent than subcutaneous $(\mathrm{n}=9)$. Most patients suffered from intractable partial epilepsy. After 6 months, 12 months, 24 months, and 36 months, 14/34 patients (41\%), 16/34 patients (47\%), 17/30 patients $(57 \%)$ and $12 / 20$ patients (60\%) respectively were responders. Two patients (6\%) became seizure-free. Complications related to implantation were minor: eight cases of limited cervical hypoesthesia, two minor scar infections and one Horner syndrome. Adverse events (voice hoarseness, throat paresthesia, coughing) related to stimulation were generally mild and tended to wane over time. However, a reduction in seizure frequency did not translate into a reduction in medication, as only $9 \%$ of responders had less antiepileptic medication at last follow-up compared to baseline. Conclusion: VNS as practiced at Notre-Dame hospital is an efficacious and safe treatment for refractory epilepsy. Quotas allotted to epilepsy centers in the province of Quebec should be lifted or increased to allow more patients to benefit from this therapeutic device.
\end{abstract}

RÉSUMÉ: Stimulation du nerf vague dans le traitement de l'épilepsie : l'expérience acquise à l'Hôpital Notre-Dame. Objectif : Il s'agit d'une étude rétrospective évaluant l'efficacité et la tolérabilité de la stimulation du nerf vague (SNV) dans le traitement de l'épilepsie réfractaire au traitement à l'Hôpital Notre-Dame. Méthode : Nous avons procédé à une revue des dossiers de tous les patients épileptiques adultes traités par SNV dont le suivi était d'un an ou plus. Les patients dont la fréquence des crises avait diminué de $50 \%$ ou plus étaient considérés comme des répondeurs. Résultats : Trente-quatre patients, 14 hommes et 20 femmes dont l'âge moyen était de 29,9 ans, ont été traités par SNV. Chez 25 patients, l'implantation était souspectorale et chez 9 elle était sous-cutanée. La plupart des patients étaient atteints d'épilepsie partielle réfractaire au traitement. Après 6 mois, 12 mois, 24 mois et 36 mois, 14/34 patients (41\%), 16/34 patients (47\%), 17/30 patients (57\%) et 12/20 patients (60\%) respectivement étaient des répondeurs. Deux patients (6\%) n'avaient plus de crises. Des complications mineures suite à l'implantation ont été observées : 8 cas d'hypoesthésie cervicale, 2 cas d'infection mineure de la cicatrice et un cas de syndrome de Horner. Les incidents thérapeutiques reliés à la stimulation (voix rauque, paresthésie de la gorge, toux) étaient généralement légers et se sont atténués avec le temps. Cependant une diminution de la fréquence des crises n'a pas entraîné de diminution de la médication et seulement $9 \%$ des répondeurs prenaient moins d'antiépileptiques qu'avant le traitement au moment du dernier examen de suivi. Conclusion : La SNV, telle qu'administrée à l'Hôpital Notre-Dame, est un traitement efficace et sûr de l'épilepsie réfractaire au traitement. Les quotas alloués aux centres de traitement de l'épilepsie au Québec devraient être levés ou augmentés pour que plus de patients puissent bénéficier de ce traitement.

Can. J. Neurol. Sci. 2011; 38: 902-908

Epilepsy is a significant neurological disorder among the Canadian population with an approximate prevalence of $0.6 \%{ }^{1}$. Despite optimal drug treatment, as many as $30 \%$ of patients will continue to have recurrent seizures ${ }^{2}$. Though epilepsy surgery may be considered, not all patients are appropriate candidates due to a poorly defined epileptogenic zone, multifocal epilepsy, an epileptogenic zone in an eloquent area, or significant comorbidities. Furthermore, some patients still continue to have disabling seizures despite epilepsy surgery. These patients are particularly at risk for sudden unexplained death in epilepsy, with a rate of 1 in 150 person-years ${ }^{3}$. The Vagus Nerve Stimulator (VNS) (Cyberonics, Inc., Houston, TX) is a nonpharmacological device approved in Canada since 1997 for use as an adjunctive therapy to reduce the frequency of seizures in patients whose epileptic disorder is dominated by partial seizures (with or without secondary generalization) or generalized seizures that are refractory to antiepileptic drugs (AEDs). Five clinical studies of VNS therapy involving 454 patients, including two randomized, blinded, active control trials, have demonstrated its efficacy and safety ${ }^{4-6}$. The device consists of a programmable generator and an electrode. The battery-powered generator is implanted subcutaneously in the subclavicular area and the bipolar helical lead electrode is attached around the left vagus nerve at the level of the neck. Vagus Nerve Stimulator parameters are adjusted during outpatient visits using a wireless programming wand connected to a laptop or handheld computer. In addition to the benefit of reducing seizure frequency by nonresponsive scheduled stimulation, rare patients/caregivers have managed to abort disabling seizures by using a portable magnet at will to trigger stimulation during the aura phase.

\footnotetext{
From the Divisions of Neurology (MQ, LC, DKN) and Neurosurgery (AB), NotreDame Hospital, Montreal University Hospital Centre, Montreal, Quebec, Canada. Received February 4, 2011. Final Revisions Submitted May 16, 2011. Correspondence to: Dang K. Nguyen, Neurology Service, Notre-Dame Hospital, 1560 rue Sherbrooke Est, Montréal, Québec, H2L 4M1, Canada.
} 
Despite its approval in 1997 by Health Canada, the use of VNS remains limited nationwide. In 2009, the rate of implantation in Canada was 3.5 per million inhabitants compared to 25 per million in the United States (data from Cyberonics). Potential causes include limited funding for VNS devices in Canada, neurologists' misconceptions on VNS efficacy despite published studies, and patients' fear of adverse events. The VNS was first introduced at our center in January 2000. We recently reviewed our experience with vagus nerve stimulation in paediatric epileptic syndromes ${ }^{7}$. The purpose of the present study was to review our experience with VNS in adults with pharmacoresistant epilepsy referred to our tertiary epilepsy center, and to compare our results with those of previous studies.

\section{Methods}

This study included all patients $\geq 16$ years old treated for at least 12 months with a VNS for refractory epilepsy, implanted between January 2000 and December 2009 and followed at the Notre-Dame epilepsy clinic. The epilepsy clinic accommodates approximately 600 new patients and 4250 follow-up visits per year, from new onset epilepsy cases to complex drug-refractory patients. Current indications for VNS at our center include a) patients with drug-refractory partial epilepsy not candidate for epilepsy surgery (e.g. multifocal epilepsy, epileptogenic zone overlying eloquent cortex); b) patients who have failed epilepsy surgery; c) patients with cryptogenic or symptomatic generalized epilepsies; d) patients with idiopathic generalized epilepsy who fail to be controlled with appropriate antiepileptic drugs (from lack of efficacy or significant side effects). Patients candidate for a callosotomy were generally offered a VNS first (when available). Choice of treatment for hypothalamic hamartomas (gamma-knife, resection, disconnection, VNS) depended upon its morphological characteristics. Deep brain stimulation is currently not being offered to epileptic patients at our center.

Records (physicians' notes and seizure diaries logged in the patient's file) were reviewed for basic demographic data, results of comprehensive epilepsy evaluations [age of onset, seizure type(s), presumed cause(s)], seizure frequencies at various times pre- and post-implantation, use of AEDs before and after implantation, adverse events related to implantation and stimulation, and use of the magnet. We limited our data collection to up to three years post-implantation. Monthly seizure frequency data was obtained during follow-up visits at 6 , 12,24 and 36 months. Seizure frequency outcome post-VNS was categorized into seven groups: seizure-free, $\geq 90 \%$ seizure reduction, $\geq 75 \%$ seizure reduction, $\geq 50 \%$ seizure reduction, $\geq 25 \%$ seizure reduction, $<25 \%$ seizure reduction and no seizure reduction or worsening of the epileptic condition. Patients with $\geq 50 \%$ reduction in seizure frequency compared to baseline (i.e. the first four groups) were considered responders to VNS therapy. To compare the number of AEDs before implantation with the last follow-up, a Wilcoxon Signed Rank test was performed.

The VNS therapy system was implanted in each patient by the same neurosurgeon $(\mathrm{AB})$. Initially, the generator was placed in a subcutaneous pocket inferior to the left clavicle. Subsequently, most generators were implanted under the pectoralis muscle for aesthetic reasons. This approach had the additional advantage of preventing the Twiddler's syndrome reported in patients with cardiac pacemakers and deep brain stimulators $^{8}$ as well as VNS (personal communication). Stimulation parameters were adjusted according to standard medical practice for VNS-implanted patients ${ }^{9}$. Medications were kept unchanged during the first year of VNS therapy. This study was approved by Notre-Dame Hospital's ethics committee and was not sponsored by the industry.

\section{RESUltS \\ Baseline data}

Between January 2000 and December 2009, a total of 34 epileptic patients (14 male $(\mathrm{M}), 20$ female $(\mathrm{F})$; mean age $=29.9)$ treated with VNS for at least 12 months were followed at our epilepsy clinic (Table). Mean age at epilepsy onset and mean duration of epilepsy before implantation were 8.8 years (range 4 months - 32 years) and 21.1 years (range $4-49$ years) respectively. Mean age at implantation was 29.9 years (range 16 to 57 years). Most patients had malformations of cortical development (cortical dysplasia, polymicrogyria, heterotopia, tuber, hypothalamic hamartoma, hemimegalencephaly) ( $\mathrm{n}=14$; $41 \%$ ) or atrophy/ gliosis from an acquired insult (meningitis, encephalitis, anoxic-ischemic brain injury) $(n=6 ; 18 \%)$. The majority suffered an epileptic disorder dominated by partial seizures with or without secondary generalization. However, two patients had refractory idiopathic generalized epilepsy. Patients had tried on average 9.6 AEDs (range 5 - 17) before receiving VNS therapy, at which point they were taking a mean of 2.9 AEDs (range 1 - 5).

\section{VNS parameters}

Parameters used in our patient population are shown in Figure 1. The most frequently employed set of parameters was a current output of 1.50 milliamps (mA) (Figure 1A), 'ON' for 30 seconds (Figure 1B), 'OFF' for five minutes (Figure 1C) for a duty cycle of $10 \%$. For all patients except one, signal frequency was set at 30 hertz $(\mathrm{Hz})$ and pulse width at $500 \mu$ seconds (s). There were no notable differences between maximal and last parameters used. Rapid cycle stimulation was tried on 11 out of 34 patients at some point in the course of their therapy. Magnet "ON" duration was $60 \mathrm{~s}$ for all patients and triggered a current intensity that was 0.75 to $1.0 \mathrm{~mA}$ greater than the regular current.

\section{Effects of VNS on seizures}

Seizure reduction rates available at 6, 12, 24 and 36 months are shown for each patient in the Table. After 6, 12, 24 and 36 months, 14/34 patients (41\%), 16/34 patients (47\%), 17/30 patients $(57 \%)$ and $12 / 20$ patients $(60 \%)$ respectively were responders (Figure 2, 3). Although some only responded transiently, 16/34 (47\%) had a sustained beneficial response for $\geq 1$ year during the three year period analyzed in this study. Two patients $(6 \%)$, \#17 with refractory juvenile myoclonic epilepsy and \#19 with intractable non-lesional frontal lobe epilepsy, became seizure-free. The effects of VNS did not differ according to seizure type except for two patients: one patient (\#4) noted a greater reduction in her occipital lobe complex partial seizures compared to her secondarily generalized tonic-clonic frontal lobe seizures while the other (\#32) reported a preferential benefit over her atonic seizures. 


\section{Table: Baseline data, post-VNS frequency reduction and impact on AEDs}

\begin{tabular}{|c|c|c|c|c|c|c|c|c|c|c|c|c|c|c|c|c|}
\hline \multirow[b]{2}{*}{$\# \mathbf{p t}$} & \multirow[b]{2}{*}{ Sex } & \multirow[b]{2}{*}{ Onset (yrs) } & \multirow{2}{*}{$\underset{\text { (yrs) }}{\text { Age at implant }}$} & \multirow[b]{2}{*}{ Site } & \multirow[b]{2}{*}{ Etiology } & \multirow{2}{*}{$\begin{array}{l}\text { Origin of } \\
\text { epilepsy }\end{array}$} & \multirow[b]{2}{*}{ Seizure type(s) } & \multirow[b]{2}{*}{ \# AED trials } & \multirow{2}{*}{$\begin{array}{c}\text { Prior } \\
\text { surgery }\end{array}$} & \multirow{2}{*}{$\begin{array}{c}\text { \#AEDs at } \\
\text { implant }\end{array}$} & \multicolumn{4}{|c|}{ Percentage of seizure reduction } & \multirow{2}{*}{$\begin{array}{l}\text { \# AEDs at } \\
\text { last FU }\end{array}$} & \multirow{2}{*}{$\begin{array}{l}\text { \#AED trials } \\
\text { post VNS }\end{array}$} \\
\hline & & & & & & & & & & & $6 \mathrm{mo}$ & $12 \mathrm{mo}$ & $24 \mathrm{mo}$ & $36 \mathrm{mo}$ & & \\
\hline 1 & F & 7 & 16 & SC & Encephalitis & Multifocal & CPS/SGTC & 9 & - & 3 & $\geq 50 \%$ & $\geq 75 \%$ & $\geq 75 \%$ & $\geq 75 \%$ & 3 & 0 \\
\hline 2 & $\mathrm{M}$ & 5 & 21 & SM & Microdysgenesis & Frontal & CPS & 10 & + & 4 & $0 \%$ & $0 \%$ & $\geq 50 \%$ & & 4 & 0 \\
\hline 3 & $\mathrm{~F}$ & 5 & 16 & $\mathrm{SC}$ & Tuberous sclerosis & Multifocal & CPS & 8 & - & 2 & $\geq 50 \%$ & $\geq 50 \%$ & $\geq 75 \%$ & $\geq 75 \%$ & 2 & 2 \\
\hline 4 & $\mathrm{~F}$ & 6 & 27 & SM & $\begin{array}{c}\text { Unknown } \\
\text { (Nonlesional) }\end{array}$ & Multifocal & CPS/SGTC & 8 & - & 2 & $\geq 75 \%$ & $\geq 90 \%$ & $\geq 50 \%$ & $\geq 50 \%$ & 5 & 4 \\
\hline 5 & $\mathrm{~F}$ & 18 & 40 & SM & $\begin{array}{c}\text { Unknown } \\
\text { (Nonlesional) }\end{array}$ & Multifocal & SPS/CPS & 8 & - & 2 & $0 \%$ & $<25 \%$ & $0 \%$ & & 2 & 1 \\
\hline 6 & F & 16 & 20 & SM & Encephalitis & Multifocal & CPS/SGTC (rare) & 8 & - & 3 & $0 \%$ & $0 \%$ & $\geq 25 \%$ & $0 \%$ & 3 & 0 \\
\hline 7 & $\bar{F}$ & 32 & 50 & SM & Encephalitis & Multifocal & CPS & 13 & - & 2 & $\geq 75 \%$ & $\geq 50 \%$ & & & 2 & 0 \\
\hline 8 & $\mathrm{M}$ & 5 & 18 & SM & Tuberous sclerosis & Frontal & CPS/SGTC & 17 & - & 4 & $0 \%$ & $0 \%$ & $0 \%$ & $0 \%$ & 4 & 0 \\
\hline 9 & $\mathrm{M}$ & 3 & 27 & SM & $\begin{array}{c}\text { Unknown } \\
\text { (Nonlesional) }\end{array}$ & Frontal & CPS/SGTC (rare) & 8 & - & 3 & $\geq 25 \%$ & $\geq 50 \%$ & $\geq 75 \%$ & $\geq 75 \%$ & 3 & 0 \\
\hline 10 & $\mathrm{~F}$ & 2 & 51 & SM & IGE & JME & $\mathrm{Abs} / \mathrm{GTC} / \mathrm{Myoc}$ & 10 & - & 4 & $\geq 75 \%$ & $\geq 75 \%$ & & & 4 & 0 \\
\hline 11 & M & $4 \mathrm{mo}$ & 21 & SM & $\begin{array}{c}\text { Cortical dysplasia }+ \\
\text { MTS }\end{array}$ & Multifocal & $\mathrm{CPS} / \mathrm{SGTC}$ & 12 & + & 3 & $0 \%$ & $0 \%$ & $\geq 50 \%$ & $\geq 50 \%$ & 4 & 2 \\
\hline 12 & F & 11 & 33 & SM & Nonlesional & Frontal & CPS/SGTC & 13 & - & 3 & $0 \%$ & $\geq 25 \%$ & $\geq 90 \%$ & $\geq 90 \%$ & 3 & 2 \\
\hline 13 & $\mathrm{~F}$ & 3 & 36 & $\mathrm{SC}$ & $\begin{array}{c}\text { Unknown } \\
\text { (Nonlesional) }\end{array}$ & Lennox-Gastaut & $\begin{array}{c}\text { GTC/Aton/Abs/CP } \\
\mathrm{S}\end{array}$ & 10 & + & 3 & $0 \%$ & $0 \%$ & $0 \%$ & $\geq 90 \%$ & 3 & 0 \\
\hline 14 & M & 20 & 40 & SM & Microdysgenesis & Frontal & $\begin{array}{c}\text { SPS/CPS/SGIC } \\
\text { (rare) }\end{array}$ & 11 & + & 2 & $0 \%$ & $<25 \%$ & $\geq 25 \%$ & $\geq 25 \%$ & 3 & 2 \\
\hline 15 & $\mathrm{M}$ & 4 & 42 & SM & $\begin{array}{l}\text { Hypoxic-ischemic } \\
\text { brain injury }\end{array}$ & Multifocal & CPS & 10 & + & 4 & $\geq 75 \%$ & $\geq 90 \%$ & $\geq 90 \%$ & & 4 & 0 \\
\hline 16 & F & 15 & 57 & SM & Microdysgenesis & Frontal & CPS & 12 & + & 5 & $\geq 25 \%$ & $0 \%$ & $\geq 25 \%$ & & 3 & 0 \\
\hline 17 & F & 12 & 32 & $\mathrm{SC}$ & IGE & JME & Myo/Abs/GTC & 8 & - & 2 & $100 \%$ & $\geq 90 \%$ & $\geq 90 \%$ & $100 \%$ & 0 & 0 \\
\hline 18 & F & 18 & 29 & SM & Heterotopia & Multifocal & SPS/CPS & 8 & - & 1 & $0 \%$ & $\geq 90 \%$ & & & 1 & 0 \\
\hline 19 & M & 7 & 35 & SM & $\begin{array}{c}\text { Unknown } \\
\text { (Nonlesional) }\end{array}$ & Frontal & $\begin{array}{c}\text { SPS/CPS/GTC } \\
\text { (rare) }\end{array}$ & 8 & - & 3 & $100 \%$ & $\geq 90 \%$ & $100 \%$ & $100 \%$ & 3 & 1 \\
\hline 20 & M & 14 & 18 & SM & $\begin{array}{c}\text { Unknown } \\
\text { (Nonlesional) }\end{array}$ & Occipital & SPS/CPS (rare) & 10 & - & 1 & $\geq 50 \%$ & $\geq 50 \%$ & $\geq 50 \%$ & $\geq 50 \%$ & 2 & 2 \\
\hline 21 & $\mathrm{M}$ & $5 \mathrm{mo}$ & 22 & $\mathrm{SC}$ & $\begin{array}{c}\text { Unknown } \\
\text { (Nonlesional) }\end{array}$ & Lennox-Gastaut & $\begin{array}{c}\text { tonic/CPS/AtyA/G } \\
\text { TC/Aton }\end{array}$ & 9 & + & 4 & $0 \%$ & $0 \%$ & $\geq 75 \%$ & $0 \%$ & 4 & 1 \\
\hline 22 & $\mathrm{~F}$ & 4 & 32 & $\mathrm{SM}$ & $\begin{array}{c}\text { Hemi- } \\
\text { megalencephalia }\end{array}$ & Frontal & $\mathrm{CPS} / \mathrm{SGTC}$ & 5 & - & 3 & $0 \%$ & $0 \%$ & $0 \%$ & & 2 & 1 \\
\hline 23 & M & 2 & 21 & SM & Polymicrogyria & Left perisylvian & CPS/SGTC & 6 & - & 2 & $\geq 50 \%$ & $\geq 50 \%$ & $\geq 50 \%$ & & 2 & 0 \\
\hline 24 & $\mathrm{~F}$ & 3 & 27 & SM & Cortical dysplasia & Parieto-occipital & $\mathrm{CPS} / \mathrm{SGTC}$ & 8 & + & 3 & $0 \%$ & $0 \%$ & & & 3 & 0 \\
\hline 25 & $\mathrm{~F}$ & 16 & 21 & SM & $\begin{array}{l}\text { Polymicrogyria + } \\
\text { heterotopias }\end{array}$ & L perisylvian & CPS/SPS (mostly) & 7 & - & 2 & $0 \%$ & $\geq 25 \%$ & $\geq 25 \%$ & $0 \%$ & 2 & 3 \\
\hline 26 & $\mathrm{~F}$ & 5 & 31 & $\mathrm{SC}$ & Hamartoma & Hypothalamus & $\begin{array}{c}\text { CPS } \\
\text { (gelastic)/SGTC }\end{array}$ & 8 & - & 4 & $\geq 50 \%$ & $\geq 50 \%$ & $\geq 75 \%$ & & 4 & 2 \\
\hline 27 & M & 3 & 21 & $\mathrm{SC}$ & $\begin{array}{l}\text { Unknown (cerebral } \\
\text { hemi-atrophy) }\end{array}$ & Lennox-Gastaut & AtyA/Tonic/Aton & 9 & - & 3 & $\geq 50 \%$ & $0 \%$ & $\geq 50 \%$ & $\geq 75 \%$ & 3 & 0 \\
\hline 28 & F & 14 & 28 & SM & $\begin{array}{c}\text { Polymicrogyria }+ \\
\text { heterotopia }\end{array}$ & $\begin{array}{c}\text { Bilateral } \\
\text { perisylvian }\end{array}$ & $\begin{array}{c}\text { CPS } \\
\text { (mostly)/SGTC }\end{array}$ & 10 & - & 3 & $0 \%$ & $\geq 50 \%$ & $\geq 75 \%$ & $\geq 50 \%$ & 4 & 3 \\
\hline 29 & $\mathrm{~F}$ & 13 & 46 & SM & Meningitis & Multifocal & $\begin{array}{c}\text { CPS } \\
\text { (mostly)/SGTC }\end{array}$ & 8 & - & 3 & $<25 \%$ & $\geq 75 \%$ & $0 \%$ & $0 \%$ & 3 & 0 \\
\hline 30 & $\mathrm{~F}$ & 5 & 33 & $\mathrm{SC}$ & $\begin{array}{l}\text { Hypoxic-ischemic } \\
\text { brain injury }\end{array}$ & Multifocal & Aton/CPS/SGTC & 9 & - & 3 & $\geq 25 \%$ & $\geq 25 \%$ & $0 \%$ & $<25 \%$ & 4 & 4 \\
\hline 31 & $\mathrm{~F}$ & 15 & 21 & SM & $\begin{array}{c}\text { Unknown } \\
\text { (Nonlesional) }\end{array}$ & Multifocal & $\begin{array}{c}\text { AtyA/Aton/CPST/S } \\
\text { GTC }\end{array}$ & 11 & + & 3 & $0 \%$ & $0 \%$ & $0 \%$ & & 3 & 4 \\
\hline 32 & M & 9 & 24 & SM & Polymicrogyria & $\begin{array}{c}\text { Bilateral } \\
\text { perisylvian }\end{array}$ & $\begin{array}{c}\text { AtyA/CPS/Aton/S } \\
\text { GTC (rare) }\end{array}$ & 11 & - & 3 & $\geq 75 \%$ & $\geq 75 \%$ & $0 \%$ & & 3 & 0 \\
\hline 33 & M & 2 & 25 & $\mathrm{SC}$ & $\begin{array}{c}\text { Unknown } \\
\text { (Nonlesional) }\end{array}$ & Lennox-Gastaut & AtyA/Tonic/SGTC & 12 & + & 4 & $<25 \%$ & $0 \%$ & $\geq 50 \%$ & $\geq 25 \%$ & 5 & 1 \\
\hline 34 & M & 3 & 35 & SM & $\begin{array}{c}\text { Unknown } \\
\text { (Nonlesional) }\end{array}$ & Lennox-Gastaut & AtyA/tonic/CPS & 11 & + & 3 & $\geq 50 \%$ & $\geq 25 \%$ & $<25 \%$ & & 3 & 0 \\
\hline
\end{tabular}

SC, subcutaneous; SM, submuscular; IGE, idiopathic generalized epilepsy; JME, juvenile myoclonic epilepsy; MTS, mesial temporal sclerosis; CPS, complex partial seizure; SGTC, secondary generalized tonic-clonic seizures; Abs, absence; Myoc, myoclonic seizures; GTC, generalized tonic-clonic seizures; AtyA, atypical absences; Aton, atonic seizures; AEDs, antiepileptic drugs; Multi, multifocal; Temp, temporal lobe; General, generalized; Occipit, occipital lobe; mo, months; yrs, years; L, left; FU, follow-up. 


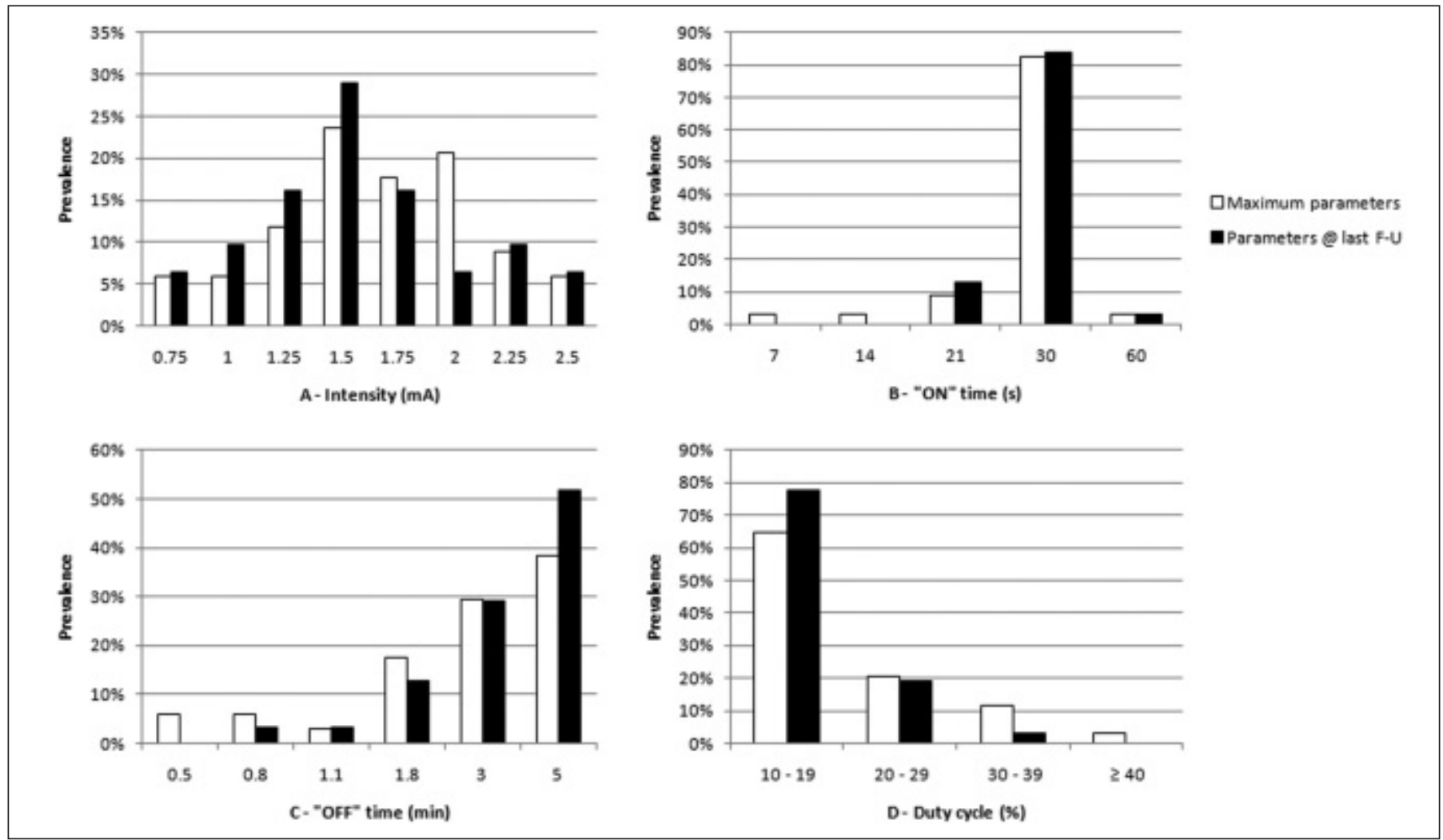

Figure 1: Maximal parameters and parameters at last follow-up. mA, milliamperes; s, seconds; min, minutes.

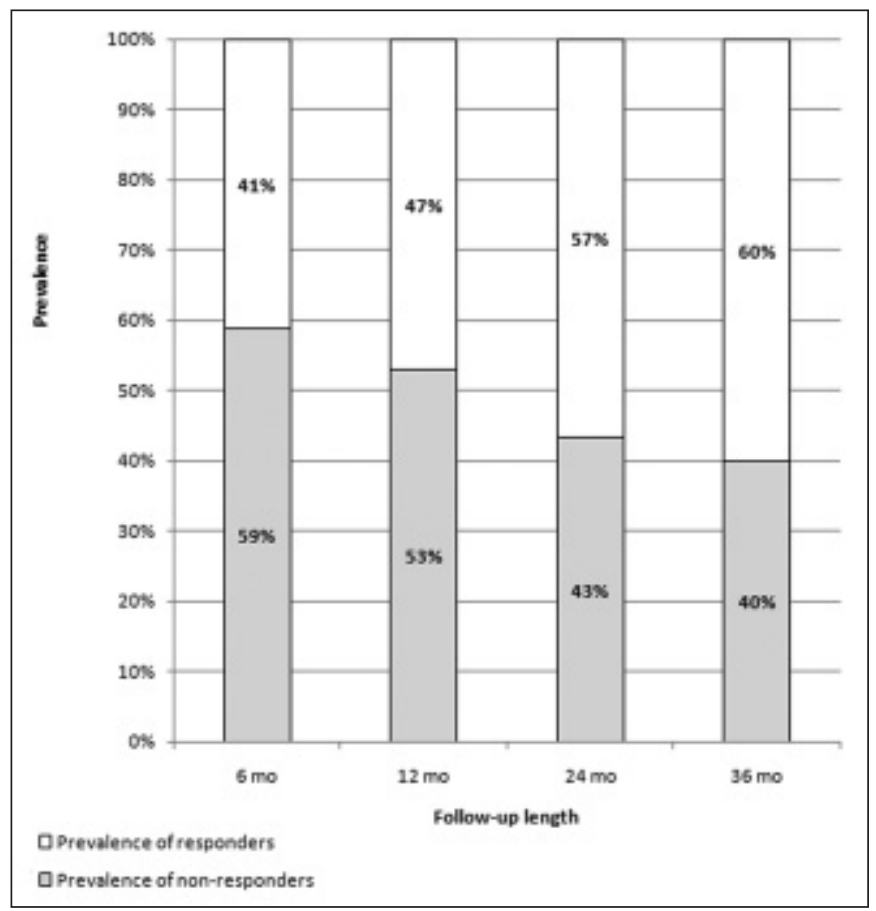

Figure 2: 50\% responder rates at chosen follow-up. There is a gradual increase of responder rates over time. The 50\% responder rate is the percentage of patients who experience a $50 \%$ or greater reduction in seizure frequency as compared to their baseline seizure frequency.

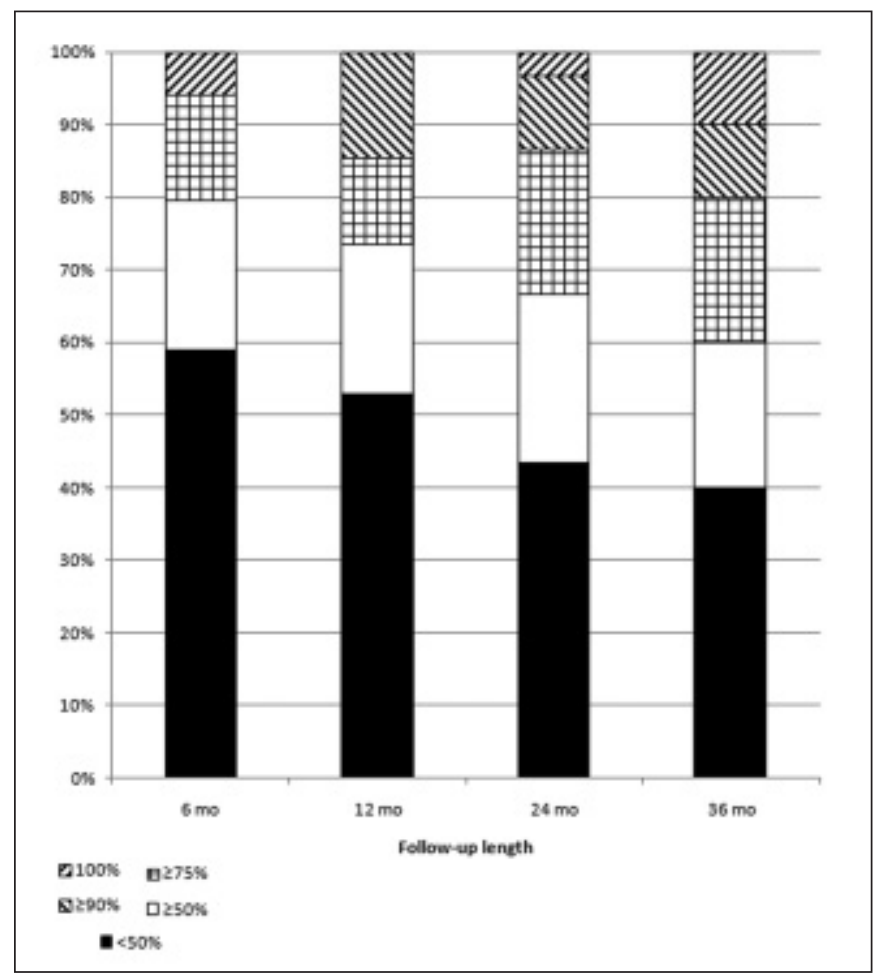

Figure 3: Seizure frequency reduction composition in responders at chosen follow-up. There is an increase in VNS efficacy over time as reflected by the greater reduction in seizure frequency and higher prevalence of responders. 
Nine patients (26\%) felt that use of the magnet had a beneficial effect: 7/9 patients reported that the magnet could abort a seizure if used early enough during the aura while the two remaining patients believed the magnet shortened the ictal and postictal durations. According to patients or caregivers, multiple magnet use was often required to stop a seizure. Three patients reported a decrease of magnet efficacy over time.

\section{Medication modifications following VNS}

The mean number of AEDs used by each patient at last follow-up (3.0) was not statistically different from the time of implantation (2.9) ( $\mathrm{p}=0.5605$; Wilcoxon Signed Rank test) (Table). On average, one new AED trial (range $0-4$ ) was performed after one year of VNS therapy. Only 3/34 patients (9\%) had fewer AEDs after VNS therapy, including one patient free of medication at last follow-up. Most patients $(24 / 34 ; 71 \%)$ remained on the same medications and $7 / 34$ patients $(21 \%)$ had even more AEDs administered daily than previously. In the subgroup of responders at last follow-up, 1/19 (5\%) had fewer AEDs after VNS therapy.

\section{Complications related to VNS implantation and stimulation- related side effects}

In terms of surgery-related adverse events, cervical hypoesthesia was reported by eight patients $(24 \%)$, with partial sensory recovery over the course of months. There were two minor scar infections (one involving the axillar scar and the other over the cervical scar) at 6 and 12 months respectively after VNS implantation. All resolved after antibiotics and did not require device removal. Finally, one patient developed a persistent left Horner syndrome following VNS implantation. Twenty-five patients (74\%) had their generator implanted between the chest wall and the pectoralis major muscle compared to nine patients $(26 \%)$ who had their generator placed subcutaneously. There was no difference in surgery-related complications between both groups. Deeper location of the generator did not affect the ability to interrogate the generator. The most commonly reported side effect from stimulation was voice hoarseness (Figure 4). Less frequent complaints were coughing, pain (throat, neck, jaw, tooth or headache), cervical paresthesias, dyspnea, and dysphagia. Stimulation-related side effects tended to regress with time. There was no left vocal cord paralysis, lower facial weakness or adverse cardiac events. No dysfunction in the stimulator or in the batteries was noted.

\section{DiscuSSION}

Two double-blind, randomized, controlled studies performed in the 1990s have established the efficacy and safety of VNS for the treatment of refractory partial seizures, paving the way for its approval by Health Canada in 19974,5. Two prospective, longterm, follow-up studies have shown sustained efficacy and tolerability over time ${ }^{6,10-13}$. Improvement is not immediate but

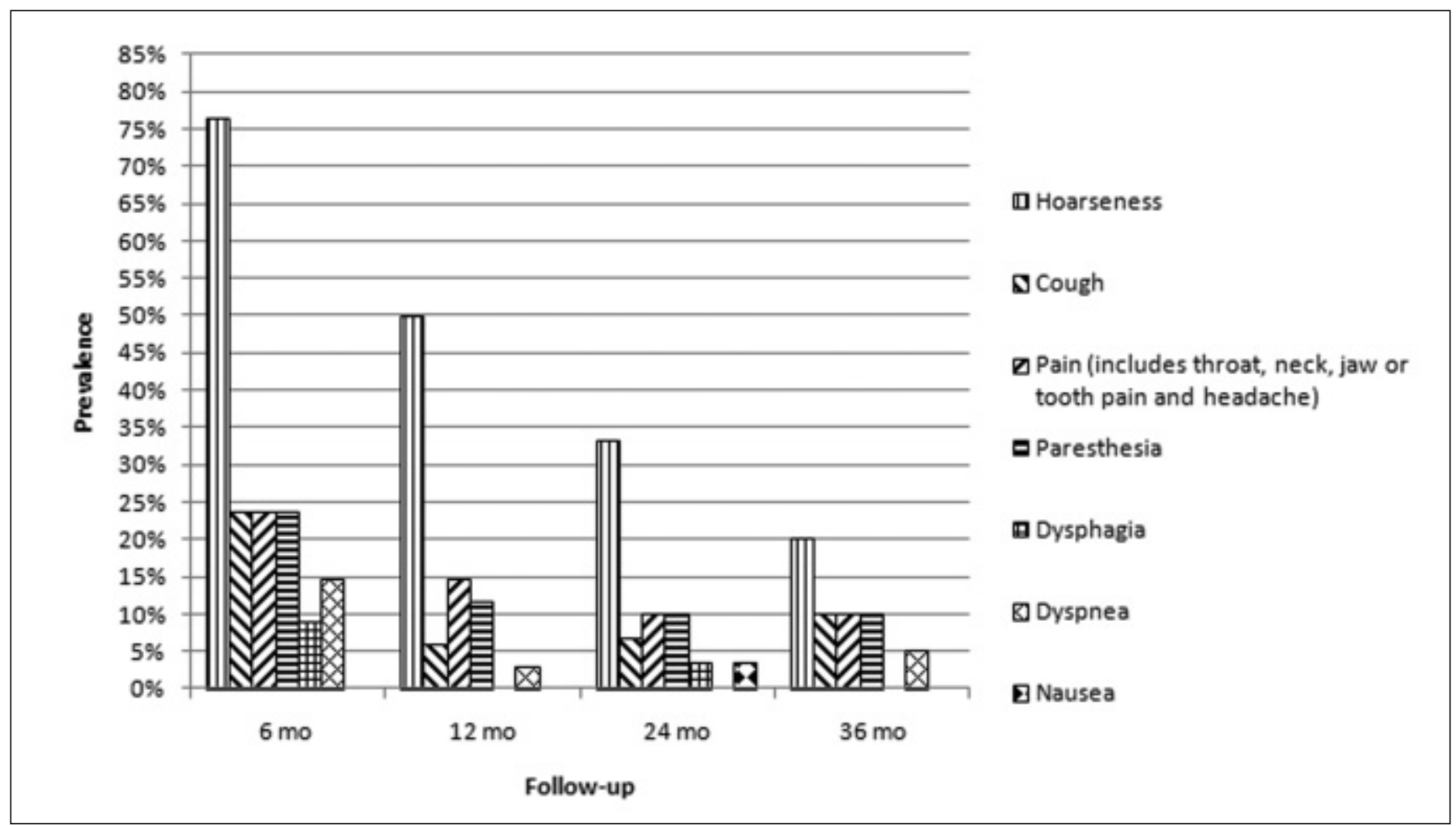

Figure 4: Stimulation-related adverse events. Prevalence of different symptoms at chosen follow-up. They tend to get milder over time. 
tends to increase over 18-24 months of treatment. Despite these studies and several other subsequent positive open-label retrospective studies ${ }^{14-19}$, use of VNS remains limited in Canada. The implant rate per million inhabitants is 3.5 in Canada compared to 25 in the United States, 16.7 in Norway, 10.7 in Sweden and 7.4 in Great Britain-Ireland (data from Cyberonics). In Quebec, the current implant rate is 4.25 patients per million, i.e. less than $0.5 \%$ of the pharmacoresistant epilepsy population. In contrast, approximately $2.5 \%$ of pharmacoresistant epilepsy patients in the United States receive VNS therapy (data from Cyberonics).

Possible reasons for underutilization of VNS therapy include Canadian neurologists' misconceptions of its efficacy despite level I and II evidence, patients' ignorance of its existence or fear of adverse events, and lack of funding. Our study, the first reported Canadian series of adult epileptics treated with VNS, demonstrated its efficacy and tolerability in pharmacoresistant epileptics with a responder rate of $41 \%, 47 \%, 57 \%$ and $60 \%$ at 6 , 12,24 and 36 months respectively. This is similar to previous studies that have reported responder rates between 35 and $64 \%{ }^{5,6,13-18}$. Furthermore, $6 \%$ of our cohort became seizure-free, in line with other studies reporting seizure-free rates ranging from 0 to $8.3 \%^{17,20-23}$ in the adult population and $11-14 \%^{7,24}$ in the paediatric population. Despite improvement on seizure frequency, only few patients benefited from medication reduction, as was also noted in our paediatric cohort ${ }^{7}$. On average, one new AED trial was attempted after a year of VNS therapy. This raises the possibility that the higher long-term responder rates reported in VNS studies are partly related to medication changes. This issue is unlikely to be resolved soon as a large randomized controlled study would be costly, possibly unethical, and have high drop out rates. Operative complications were few, consisting mainly of local minor infections and partly expected cervical hypoesthesia. Stimulus-related side effects, mainly coughing, throat pain and hoarseness, tended to improve with time, in concordance with other studies ${ }^{10}$. Implantation of the generator submuscularly instead of subcutaneously did not result in increased difficulty communicating with the device but minimized the risk of Twiddler's syndrome, and was cosmetically more appreciated by patients.

The biggest deterrent to the use of VNS in Canada probably lies in the lack of funding ${ }^{25}$. Because VNS is much more costly than antiepileptic drugs (approximately \$23 800 per device), the Health Ministry imposes a quota on epilepsy centers in the province of Quebec and elsewhere. For example, in the greater Montreal area, budget allocation allows implantation of approximately 6 to 10 VNS devices per year for the two paediatric epilepsy centers and 3 to 4 for the two adult epilepsy centers, despite providing tertiary epilepsy care to more than half of the population of the province of Quebec (7,750,504 people). To put things in perspective, more than 2000 cardiac pacemakers and 1500 implantable defibrillators are implanted or revised annually in the province without restrictions ${ }^{26,27}$. These VNS quotas have resulted in significant waiting lists, with the adverse consequence that only the most refractory patients are added to the list (as reflected by the high number of antiepileptic drugs tried by the patients in our study before being implanted). A multicenter study, comparing a group of patients treated with VNS therapy earlier in the course of their epilepsy with a group treated with VNS therapy later in the course, showed that earlier use of VNS therapy significantly improved seizure control. Of the patients in the early group treated within five years after onset or having tried four or fewer antiepileptic drugs, $15 \%$ reported no seizures with VNS at three months compared with $4.4 \%$ of those in the control group ${ }^{28}$. Recent health economic studies have demonstrated that patients spent less time in hospital (emergency room visits, ward stays, intensive care unit use) after being treated with $\mathrm{VNS}^{29,30}$.

Finally, there is an urgent need to readjust quotas allocated to adult epilepsy centers because paediatric epilepsy centers are currently implanting almost twice as many VNS devices as adult epilepsy centers. Considering that approximately two thirds of patients elect to replace their batteries after approximately 7-10 years $^{31}$, there is a risk that adult epilepsy centers may no longer be able to do new implants due to the need to replace the dying batteries of former paediatric patients transferred to adult centers for continuing care. Ideally, an expert panel should be convened by the Health Ministry to evaluate short term needs, establish projections and develop a comprehensive policy, not only VNS but also neurostimulation in general for the treatment of epilepsy, considering recent positive results with deep brain stimulation $^{32}$ and responsive neurostimulation ${ }^{33}$.

\section{CONCLUSION}

In summary, VNS as practiced at Notre-Dame hospital is an efficacious and safe treatment for refractory epilepsy. Quotas allotted to epilepsy centers in the province of Quebec and the rest of Canada should be lifted or increased to allow more patients to benefit from this therapeutic device.

\section{ACKNOWLEDGEMENTS}

The authors thank the personnel of the Notre-Dame epilepsy clinic and EEG laboratory. Q.M. was supported by a research COPSE grant from the University of Montréal.

\section{REFERENCES}

1. Tellez-Zenteno JF, Pondal-Sordo M, Matijevic S, Wiebe S. National and regional prevalence of self-reported epilepsy in Canada. Epilepsia. 2004;45(12):1623-9.

2. Kwan P, Brodie MJ. Early identification of refractory epilepsy. N Engl J Med. 2000;342(5):314-9.

3. So EL, Bainbridge J, Buchhalter JR, et al. Report of the American Epilepsy Society and the Epilepsy Foundation joint task force on sudden unexplained death in epilepsy. Epilepsia. 2009;50(4): 917-22.

4. Ben-Menachem E, Manon-Espaillat R, Ristanovic R, et al. Vagus nerve stimulation for treatment of partial seizures. 1. A controlled study of effect on seizures. First International Vagus Nerve Study Group. Epilepsia. 1994;35(3):616-26.

5. Handforth A, DeGiorgio CM, Schachter SC, et al. Vagus nerve stimulation therapy for partial-onset seizures: a randomized active-control trial. Neurology. 1998;51(1):48-55.

6. Morris GL, Mueller WM. Long-term treatment with vagus nerve stimulation in patients with refractory epilepsy. The Vagus Nerve Stimulation Study Group E01-E05. Neurology. 1999;53(8): 1731-5.

7. Rossignol E, Lortie A, Thomas T, et al. Vagus nerve stimulation in pediatric epileptic syndromes. Seizure. 2009;18(1):34-7 .

8. Nicholson WJ, Tuohy KA,Tilkemeier P. Twiddler's syndrome. N Engl J Med. 2003;348(17):1726-7.

9. Heck C, Helmers SL, DeGiorgio CM. Vagus nerve stimulation therapy, epilepsy, and device parameters: scientific basis and recommendations for use. Neurology. 2002;59(6 Suppl 4):S31-7. 
10. DeGiorgio CM, Schachter SC, Handforth A, et al. Prospective longterm study of vagus nerve stimulation for the treatment of refractory seizures. Epilepsia. 2000;41(9):1195-200.

11. Schachter SC. Vagus nerve stimulation therapy summary. Five years after FDA approval. Neurology. 2002;59(6 Suppl 4): S15-20.

12. Ardesch JJ, Buschman HP, Wagener-Schimmel LJ, van der Aa HE, Hageman G. Vagus nerve stimulation for medically refractory epilepsy; a long-term follow-up study. Seizure. 2007;16(7): 579-85.

13. Kuba R, Brázdil M, Kalina M, et al. Vagus nerve stimulation: longitudinal follow-up of patients treated for 5 years. Seizure. 2009;18(4):269-74.

14. Boon P, Vonck K, Van Walleghem P, et al. Programmed and magnet-induced vagus nerve stimulation for refractory epilepsy. J Clin Neurophysiol. 2001;18(5):402-7.

15. Scherrmann J, Hoppe C, Kral T, et al. Vagus nerve stimulation: clinical experience in a large patient series. J Clin Neurophysiol. 2001;18(5):408-14.

16. Vonck K, Thadani V, Gilbert K, et al. Vagus nerve stimulation for refractory epilepsy: a transatlantic experience. J Clin Neurophysiol. 2004;21(4):283-9.

17. Amar AP, Apuzzo ML, Liu CY. Vagus nerve stimulation therapy after failed cranial surgery for intractable epilepsy: results from the vagus nerve stimulation therapy patient outcome registry. Neurosurgery. 2004;55(5):1086-93.

18. De Herdt V, Boon P, Ceulemans B, et al. Vagus nerve stimulation for refractory epilepsy: a Belgian multicenter study. Eur J Paediatr Neurol. 2007;11(5):261-9.

19. Muller K, Fabo D, Entz L, et al. Outcome of vagus nerve stimulation for epilepsy in Budapest. Epilepsia. 2010;51(Suppl 3):98-101.

20. Ghaemi K, Elsharkawy AE, Schulz R, et al. Vagus nerve stimulation: outcome and predictors of seizure freedom in longterm follow-up. Seizure. 2010;19(5):264-8

21. Alonso-Vanegas MA, Austria-Velásquez J, López-Gómez M, BrustMascher E. Chronic intermittent vagal nerve stimulation in the treatment of refractory epilepsy: experience in Mexico with 35 cases. Cir Cir. 2010;78(1):15-23,24

22. Wheeler M, De Herdt V, Vonck K, et al. Efficacy of vagus nerve stimulation for refractory epilepsy among patient subgroups: A re-analysis using the Engel classification. Seizure. 2011 Jan 25. [Epub ahead of print]
23. El Tahry R, De Herdt V, Raedt R, et al. Evolution in VNS therapy for refractory epilepsy, experience with Demipulse devices at Ghent University Hospital. Seizure. 2010;19(9):531-5.

24. Franzoni E, Gentile V, Colonelli MC, et al. VNS in drug resistant epilepsy: preliminary report on a small group of patients. Ital $\mathbf{J}$ Pediatr. 2010;36:30.

25. Guberman A. Vagus nerve stimulation in the treatment of epilepsy. CMAJ. 2004;171(10):1165-6.

26. Ho $\mathrm{C}, \mathrm{Li} \mathrm{H}$, Noorani $\mathrm{H}$, et al. Implantable cardiac defibrillators for primary prevention of sudden cardiac death in high risk patients: a meta-analysis of clinical efficacy, and a review of costeffectiveness and psychosocial issues [Technology report no 81]. Ottawa: Canadian Agency for Drugs and Technologies in Health; 2007.

27. Groupe d'experts en électrophysiologie cardiaque du réseau québécois de cardiologie tertiaire. Évaluation des besoins: tendances et projections 2007-2010. Québec: La Direction des communications du ministère de la Santé et des Services sociaux du Québec; 2007 Nov. 51 p.

28. Renfroe JB, Wheless JW. Earlier use of adjunctive vagus nerve stimulation therapy for refractory epilepsy. Neurology. 2002;59 (6 Suppl 4):S26-30

29. Boon P, D'Havé M, Van Walleghem P, et al. Direct medical costs of refractory epilepsy incurred by three different treatment modalities: a prospective assessment. Epilepsia. 2002;43(1): 96-102.

30. Ben-Menachem E, Hellström K, Verstappen D. Analysis of direct hospital costs before and 18 months after treatment with vagus nerve stimulation therapy in 43 patients. Neurology. 2002;59(6 Suppl 4):S44-7.

31. Ben-Menachem E. Vagus-nerve stimulation for the treatment of epilepsy. Lancet Neurol. 2002;1(8):477-82. Review.

32. Fisher R, Salanova V, Witt T et al. and the SANTE study group. Electrical stimulation of the anterior nucleus of thalamus for treatment of refractory epilepsy. Epilepsia. 2010;51:899-908.

33. Morrell MJ and the RNS System Pivotal Investigators. Results of a multicenter double blinded randomized controlled pivotal investigation of the RNS system for treatment of intractable partial epilepsy in adults [abstract]. Epilepsia. 2009;50(Suppl. 11):1-502. 